\title{
Pedagogical Stimulation of University Students' Social Competence Development by Means of Interdisciplinary Integration
}

\author{
Gulnara I. Salyakhova ${ }^{1} \&$ Roza A. Valeeva ${ }^{1}$ \\ ${ }^{1}$ Kazan (Volga region) Federal University, Kazan, Russia \\ Correspondence: Roza A. Valeeva, Kazan (Volga region) Federal University, Kremlyovskaya Street 18, Kazan, \\ 420008, Russia. E-mail: valeykin@yandex.ru
}

Received: January 19, 2014 Accepted: February 22, 2015 Online Published: March 30, 2015

doi:10.5539/res.v7n5p186 URL: http://dx.doi.org/10.5539/res.v7n5p186

\begin{abstract}
The most important component of social and economic development of the country is knowledge and information requiring mastery of higher education. The new paradigm of higher education is not training only to obtain specific knowledge but to learn to adapt to a qualitatively different conditions of life, to work in an ever-changing socio-economic environment. Successful career of the young specialist after graduation and application of acquired knowledge and skills in practice depend on the formation of key competencies in an educational institution. Nowadays Russian society demands specific results of vocational education meaning not only graduates' professional knowledge but his practical readiness for activities in standard and non-standard situations of professional life.

The article is devoted to special educational outcomes of vocational education in which knowledge is a necessary but not sufficient condition for achieving the required quality. It deals with the professional competence and its components such as vocational and key (basic) competences. The article describes the features of pedagogical stimulation of university students' social competence development by means of interdisciplinary integration. It defines the concept "social competence" and describes pedagogical conditions for stimulation of university students' social competence development. The study puts forward the indicators of social competence formation and presents the results of experimental work on university students' social competence development.
\end{abstract}

Keywords: social competence, pedagogical stimulation, interdisciplinary integration, foreign language, psychology, pedagogical model, university students

\section{Introduction}

\subsection{Actualizing the Problem}

The problem of future specialists' readiness for self-responsibility and choice of action in the political, economic and cultural life is actualized in modern Russia. Different severities of social and economic life influence directly the younger generation. According to the survey, a lot of graduates have a lack of social interaction skills. Future specialists have no experience of cooperation in groups, they are not able to find constructive solutions to complex conflict situations, and they often have no developed social competences as well. This trend requires a rethinking of the goals and outcomes of education. One of the most important results of higher education should be a willingness and ability of young people to take personal responsibility for their own welfare and the welfare of society, the formation of core competencies necessary for life (Kalimullin, 2014). Among the competencies necessary for their successful functioning in the society special attention is paid to social competence. This competence means constructive building one's relationships with others; establishing and maintaining contacts; the ability to be responsible, to participate in making group decisions, to resolve conflict peacefully (Ivanenko et al., 2015). In this regard the development of social competence of students in the learning process at the university becomes an important and urgent task of higher education.

\subsection{Explore Importance of the Problem}

Socio-economic changes in Russia have led to the need of modernizing a lot of social institutions including the higher education system which is directly linked to economic processes. Vocational education is the most important social institution training the young people for solving future professional tasks in a certain field of 
their activity. It suggests a high level of special skills development and the ability of their continuous improving. But this is not limited to the function of higher education. It is also designed to form a number of non-professional abilities including:

- Forming students' skills to perceive the world holistically and have a sense of unity with it;

- Mastering the technology of optimal decision making; the ability to adapt to various changes; predicting the course of arising situation in the course of activities; preventing the negative effects of extreme events;

- Forming tolerance in judgment and action.

This actualizes the importance of investigating the conditions of students' social competence development while studying in higher education institution.

\subsection{Objectives of Pedagogical Stimulation of University Students'Social Competence Development}

Development of students' social competence in the learning process is related to the global goal of the educational system - the development of student's personality, his intellectual, emotional, volitional personal qualities as well as purposefulness, responsibility, humanity, tolerance, citizenship and others (Valeeva et al., 2014). The tasks of stimulation the development of social competence include helping students in gaining the knowledge of themselves, their abilities and capabilities, their interests, aptitudes and the establishment on this basis of their professional orientation; developing their communicativeness (responsiveness in communicating, structuring speech, persuasive argument, handling objections, etc.); ability to work in a team; ability to clearly and convincingly make a presentation of their ideas; readiness for non-standard creative solutions; self-organization skills; flexibility to new requirements; endurance and determination; forming ability and willingness of students to treat themselves and their partners constructively with the desire for cooperation and taking into account the current situation of communication; preparing them to fulfill their civic duties, familiarization with the legal provisions in force in society.

\subsection{Status of a Problem}

Various aspects of social competence have been studied quite extensively in Russian psycho-pedagogical researches. Ideas of competence approach in education are considered by Baydenko (2005), Zimnyaya (2006). Key competencies were investigated by Khutorskoy (2003). Theoretical justification of the essence of the concept "competence" is presented by Shishov (1999). Social and psychological competence was studied by Berestova (1994). Communicative competence was studied by Zhukov, Petrovskaya and Rastyannikov (1990); autopsychological competence was studied by Sitnikov, Derkach and Elshina (1994); reflexive competence was studied by Polishchuk (1995), Biktagirova and Valeeva (2014); intercultural competence was studied by Grigorieva (2004); information competence was studied by Kulbeda (2005), Vlasova, Kirilova and Masalimova (2015). Theory of communication and social relations of the individual, his socialization and social adaptation was studied by Bodalev (1995), Mudrik (2001), Masalimova and Sabirova (2014, 2015), Shaidullina et al. (2015), Ivanenko et al (2015). Egorov (2003) emphasizes the need for greater attention to the development of social competence, for it is a generalized quality contributing the successful implementation of its certain social roles. Complex of scientific ideas about social competences of the person was researched by Bakhteeva (2004), Mosyagina (2008), Valeeva and Karimova (2014). Ideas of social intelligence are presented in the works of Kunitsyna (1995). The process of pre-school children social competence development was disclosed by Belotserkovets (2002), of elementary school students - by Kalinina (2003) and of teenagers - by Lukyanova (2001). Development of social competence of students was studied by Kolobova (2003), of orphans-by Kazantseva (1999). Problems of pedagogical stimulation were reflected in the works of Glickman (2007), Pryanikova (1992). Certain aspects of improving learning from the perspective of interdisciplinary connections and integration in education were considered by Zverev and Maximova (1987), Kolyagin (1990).

\subsection{Hypothesis}

Pedagogical stimulation of the development of social competence of students in the course of their training at the university will be effective if pedagogical potential of interdisciplinary integration of the humanities "foreign language" and "psychology" is used as an effective stimulus means generating skills of constructive interaction with people, self-regulation and self-control.

\section{Materials and Methods}

\subsection{The Tasks of the Research}

The study addressed the following tasks: 1) to determine the content and the essential characteristics of pedagogical stimulation of university students' social competence development; 2) to disclose the pedagogical 
potential of interdisciplinary integration of foreign language and psychology courses as an effective stimulus means of the students' social competence development; 4) to develop and test during the experimental work the effectiveness of interdisciplinary integration of foreign language and psychology courses in students' social competence development.

\subsection{Theoretical and Empirical Methods}

Problem solving and testing of assumptions were provided by a complex of complementary methods:

- Theoretical methods - theoretical analysis and synthesis, generalization of experience, modeling;

- Empirical methods - observation, survey questionnaire, testing;

- Statistics methods - quantitative and qualitative materials processing, methods of mathematical statistics, multiple comparison.

\subsection{The Trial Infrastructure and Stages of the Research}

Experimental base of the research were departments of Mathematics, Geography, Biology of Kazan (Volga region) Federal University. 120 full-time training students of the second, third and fourth years of took part in this research. Experimental study had three stages (ascertaining, forming and controlling) and was carried out from 2010 to 2014.

On the first stage - search and theoretical phase (2010-2011), there was carried out an analysis of theoretical approaches to the problem, the scientific research apparatus was determined, experimental technique was chosen.

The second experimental stage (2012-2013) was associated with the pedagogical experiment. The development and testing of a pedagogical model to promote the process of students' social competence development was carried out; the pedagogical potential of interdisciplinary integration of foreign language and psychology courses in the development of students' social competence was detected.

On the third synthesis stage (2013-2014) the experimental work was finished, interpretation of research results was carried out, theoretical propositions and conclusions were refined.

\subsection{Evaluation Criteria}

During the experiment there were determined indicators and criteria of students' social competence. For the indicators characterizing the level of social competence development we accepted the following:

- Intellectual and cognitive indicator (the ability to understand the intentions, feelings and emotional state of a person by verbal and nonverbal manifestations; the ability to demonstrate foresight in interpersonal relationship and skills to predict successfully the most likely reaction of people);

- Emotionally empathetic indicator (reflects the ability to understand the feelings and states of another person, the ability to control his emotions; the ability to empathize and participate; lightness, mobility and flexibility of emotions);

- Communicative and behavioral indicator (suggests communicative abilities, the ability to use productive behavior in conflict situations).

\subsection{Experimental Procedure and Its Description}

In the ascertaining stage of the experiment there was carried out diagnostics of the initial level of development of students' social competence. Methods of measuring intellectual-cognitive, emotionally-empathetic and communicative and behavioral indicators of students' social competence were chosen. For the diagnosis of intellectual and cognitive indicators we used the Guilford's test identifying the level of social intelligence.

To assess emotional empathy index of social competence we applied V. V Boyko's methodology for diagnosing the empathic abilities level. The questionnaire includes 36 questions. The respondents were required to answer "yes" or "no" to each question. Then we counted the number of correct answers for each of the 6 scales and then determined the total score. We analyzed indicators of the individual scales and overall assessment of the total level of empathy. It covered the following scale: a rational channel empathy, emotional channel empathy, intuitive channel empathy, attitudes promoting empathy, the penetrating power of empathy, identification in empathy. Estimates on scales performed a supporting role in the interpretation of the main indicator - the level of empathy. Summary indicator can theoretically range from 0 to 36 points. According to our preliminary data we assumed the following: 30 points and above - a very high level of empathy; 29-22-medium; 21-15 - understated; less than 14 points — very low. 
To study the communicative and behavioral indicators of social competence we chose K. Tomas's questionnaire. It includes 30 questions detecting the typical ways of students' responding to conflict situations (cooperation, compromise, adaptation, avoidance, competition). It was assumed that avoiding the conflict neither party could succeed. In such types of behavior as competition, accommodation and compromise only one participant is a winner and the other loses, or both lose, since going to compromise concessions. And only in a situation of cooperation both sides are winners. We also used the test to assess the development of communication skills.

The experiment was performed in the control and experimental groups. Having studied the intellectual-gnostic indicator we obtained the following empirical evidence: the level of a composite assessment of social intelligence in the experimental group is 28.5 points, which corresponds to 3 (average) level of social intelligence; in the control group-29 points (level 3). The integral indicator of empathic abilities in the first and second groups was 19 and 18 points, which corresponded to the understated level of students' empathic abilities. After analyzing the results of communicative and behavioral indicators we came to the conclusion that most of the participants in the experimental group preferred the following strategies of behavior in conflict situations: a compromise (6.8 points) and avoidance (6.8 points). And students of the control group used avoidance (6.9 points) and appliances (6.6 points) that were not a successful strategy of conflict management. Tests for determining the level of communication skills showed that the average indicators in experimental group was 0.5 points, in the control group -0.55 points, which corresponded to the below average level of communication skills. Thus, the results of the ascertaining experiment showed that the majority of students couldn't form their social competence.

\section{Results}

\subsection{Methods of Teaching to Promote the Process of University Students'Social Competence Development}

Important for the study was the issue of pedagogical stimulation mechanisms. Based on the theory of pedagogical stimulation it was concluded the need to identify the main stimulus means of students' social competence development. We identified interdisciplinary integration as such means. In accordance with the conditions of interdisciplinary integration allocated by Usova (1973) we assumed the possibility of integrating the humanities in the development of university students' social competence, namely foreign language and psychology, because they meet the conditions highlighted. Pedagogical potential of the discipline "Foreign Language" in the development of social competence is the ability to use active forms and methods of training, group forms of work (organization of polylogue, dramatization, role playing, implementation of group projects, "brainstorm", debates, discussions, etc.) contributing to the formation of students' communication skills, skills of logical presentation-making, communication, responsibility, independence, self-confidence. Psychology helps students to get information about themselves, about the motives and needs of others; improve competence in communication; develop personal qualities (empathy, tolerance, sensitivity, creativity, confidence); to learn practical communication skills (the ability to put oneself in the others' position, to defend one's point of view, to understand the other, to influence others, to listen to them, to prevent and resolve conflict, to establish and maintain contacts, to present themselves, etc.); to realize personal growth, which is manifested in the formulation of long-term goals of one's life; to change the position in life; self-realization; self-confidence; self-development; improving self-esteem.

\subsection{The Procedure and Results of the Experiment}

To carry out the experimental work we formed 2 groups of students: (60 students in each group), students of the 2 course of Kazan Federal University. The difference between the experimental and control groups was that in the control groups academic work was organized on the basis of standard program, and in the experimental groups the idea of interdisciplinary integration of humanitarian subjects in the process of students' social competence development was implemented. Continuously during the experiment the results of the effectiveness of this idea were analyzed and synthesized. This was reflected in the card of students' readiness, as well as in the process of questioning and analyzing the results.

Results obtained after the forming phase of the experiment showed the dynamics of the students' social competence development. As a result of re-investigation the following empirical data were obtained: the experimental group social intelligence composite score level increased from 28.5 to 40 points (Level 4-above average). The level of social intelligence in the control group changed slightly.

There were significant changes in the level of empathic abilities of students: the value of the integral index of empathic abilities increased from 19 to 25 points. The value of this index in the control group increased from 19 to 20 points, level of empathy was undervalued. Repeated diagnostics of the communication skills level also showed significant changes. The index value increased from 0.5 to 0.6 points indicating the average level of 
communication skills. Communication skills of students in the control group did not change.

If in the ascertaining stage the students demonstrated such strategies as "adaptation" and "avoidance", the highest point in the control stage of the strategy "partnership" was 8.9 points. This strategy is a positive behavior in conflict resolution. There were decreased scores on the strategy of "avoidance" and "adaptation" which in ascertaining stage had high rates. Analyzing the results of the average values of behavioral strategies in the control group at the control point we noted that any changes in the strategies of behavior in this group were not observed.

Comparative analysis of the results for the four methods indicated a higher level of social competence of the students in the experimental group compared with the control one. The level of social intelligence of students in the experimental group was above average. Students in this group increased the level of empathic abilities and in conflict situations they preferred cooperation as strategy of behavior; they also increased the level of communication skills.

To determine the significance of differences in mean values of the measured parameters there was used Student's t-test for independent samples; it was possible to state the existence of significant differences between the mean values of all components of competence before and after the experiment in all experimental groups.

\section{Discussions}

The basic premise which helped stimulate the development of university students' social competence is the realization in the educational process pedagogical potential of the content of university courses "Foreign language" and "Psychology" in formation skills of the constructive interaction with people, self-regulation and self-control.

Interdisciplinary integration of disciplines "Foreign language" and "Psychology" can be a factor in stimulating the process of university students' social competence development and promote self-sufficient operation of the individual in society, the adoption of new ways of life. The integrate results of this process will be:

- The development of the ability to work in a team;

- The ability to take responsibility for solving various issues;

- The ability to take the initiative;

- The ability to identify problems and find ways to solve them;

- The ability to analyze new situations and use existing knowledge for analysis;

- The ability to make decisions based on "common sense" (in the absence of the necessary information);

- The ability to persevere;

- Skills in conflict to find arguments in favor of the opposite side.

\section{Conclusion}

An important condition for the development of social competence of students is to develop the conscious attitude and positive motivation, as well as the need for mastering a foreign language speech activity. The implementation of this condition involves the selection of the content of the training material which corresponds to existing needs of students and contributes to the emergence of new ones necessary for training activities; integrated organization of training activities; the use of collective forms of learning activities. Analysis of the students' future professional activity during the course of integrated foreign language and psychology courses leads to greater mastery of social competences. This condition assumes a performance of creative tasks with content analysis of future profession situations contributing to the formation of students' communicative skills and abilities; readiness for future professional activities. It also provides an opportunity to express their opinions and feelings. Enrichment of educational material for integrated foreign language and psychological courses with situations of social interaction is realized by the use of topics and communication situations that contribute to the formation of the students' needs for social interaction. Role and business games used in the classroom stimulate the purchase of communication experience in different social roles, allow simulating different forms of activity; introduce students to behavioral stamps and teach them to take personal-social roles.

\section{Acknowledgments}

The work is performed according to the Russian Government Program of Competitive Growth of Kazan Federal University 


\section{References}

Baydenko, V. I. (2005). Competence-based approach to the design of the state educational standards of higher education. Moscow: Research Center of the quality of training problems.

Bakhteeva, S. S. (2004). Formation of social competence of the expert in the process of learning a foreign language in high school of economics. Kazan: Innovation Center.

Belotserkovets, N. I. (2002). Formation of 3-7 year old children social competence in open preschool educational institution (Doctoral dissertation). Karachaevsk.

Berestova, L. I. (1994). Socio-psychological competence as professional characteristics of the leader (Doctoral dissertation). Moscow.

Biktagirova, G. F., \& Valeeva, R. A. (2014). Development of the teachers' pedagogical reflection. Life Science Journal, 11(9), 60-63.

Bodalev, A. A. (1995). Personality and communication. Moscow: International Pedagogical Academy.

Egorov, D. E. (2003). Formation of secondary vocational schools students' social competence in the course of social education. Moscow.

Glickman, I. Z. (2007). Teacher incentives. Moscow: Prosvieshchenie.

Grigorieva, N. N. (2004). Formation of senior pupils' intercultural competence: On a material of teaching foreign languages (Doctoral dissertation). Kazan.

Ivanenko, N. A., Burdukovskaya, E. A., Yunusova, A. B., Mukhametshina, R. F., Letyaev, V. A., Islamova, L. R., \& Yeremeyeva, T. S. (2015). Corporativity as a Condition for Developing Teaching Staff. Review of European Studies, 7(4), 49-53. http://dx.doi.org/10.5539/res.v7n4p49

Ivanenko, N. A., Mustafina, G. M., Sagitova, V. R., Akhmetzyanov, I. G., Khazratova, F. V., Salakhova, I. T., \& Mokeyeva, E. V. (2015). Basic components of developing teachers' research competence as a condition to improve their competitiveness. Review of European Studies, 7(4), 221-227. http://dx.doi.org/10.5539/res.v7n4p221

Kazantseva, O. V. (1999). Features of the G. Horn game and its influence on the development of orphans' social competence. Family psychology and family therapy, 1, 37-41.

Kalimullin, A. M. (2014). Improvement of teachers' qualification at Kazan federal university. World Applied Sciences Journal, 30(4), 447-450.

Kalimullin, A. M. (2014). Stages of ecological policy development in the industrial sector of Russia in the second half of the XXth century: Historical perspective. Life Science Journal, 11(8), 492-497.

Kalinina, N. V., \& Lukyanova, M. I. (2003). Psychological aspects of students'social competence. Ulyanovsk.

Khutorskoy, A. V. (2003). Key competences. Technology of education design. Narodnoye obrazovanie, 5, 58-64.

Kolobova, O. V. (2003). Formation of classical university graduates' social competence (while learning a foreign language) (Doctoral dissertation). Ryazan.

Kolyagin, Y. M., \& Alexeenko, O. L. (1990). Integration of schooling. Elementary School, 9, 28-32.

Kulbeda, N. V. (2005). Development of students' information competence in the project activities with the computer presentation (Doctoral dissertation). Kazan.

Kunitsina, V. N. (1995). Social intelligence and social competence. St. Petersburg: St. Petersburg State University.

Lukyanova, M. I. (2001). Basic needs of the age as a basis for the development of the adolescents' social competence. Psychological Science and Education, 4, 41-47.

Masalimova, A. R., \& Sabirova, L .L. (2014). Multi-dimensional classification of types and forms of corporate education. American Journal of Applied Sciences, 11, 1054-1058. http://dx.doi.org/10.3844/ajassp.2014.1054.1058

Masalimova, A. R., \& Sabirova, L. L. (2015). Mentors and Trainees Professional Interaction Features at the Modern Enterprises in Russia. Review of European Studies, 7(4), 20-26. http://dx.doi.org/10.5539/res.v7n4p20

Mosyagina, G. P. (2008). Formation of future teachers' social competence: an example of pedagogical college 
(Doctoral dissertation). Stavropol.

Mudrik, A. V. (2001). Communication in the process of education. Moscow: Russian Pedagogical Society.

Polishchuk, O. (1995). The development of reflective competence of civil service personnel (Doctoral dissertation). Moscow.

Pryanikova, V. G. (1992). Formation and development of the pedagogical stimulation concept in the theory of Soviet pedagogy (Doctoral dissertation). Moscow.

Shaidullina, A. R., Morov, A. V., Morova, N. S., Petrova, T. N., Kirillova, O. V., Kirillova, T. V., \& Riazantzeva, I. M. (2015). The Features of Social Partnership as a Mechanism for the Integration of Education and Production. Review of European Studies, 7(3), 292-297. http://dx.doi.org/10.5539/res.v7n3p292

Shishov, S. E. (1999). The concept of competence in the context of the quality of education. Standards and monitoring in education, 2, 30-34.

Sitnikov, A. P., Derkach, A. A., \& Elshina, I. V. (1994). Autopsychological Competence of Managers: Applied Technology. Moscow: RAU.

Usova, A. V. (1973). Essence, meaning. The main directions of the implementation of interdisciplinary connections. In Improvement of teaching physics in high school (pp. 3-7). Chelyabinsk.

Valeeva, R. A., \& Karimova, L. Sh. (2014). Research of Future Pedagogue-Psychologists' Social Competency and Pedagogical Conditions of its Formation. Procedia-Social and Behavioral Sciences, 131, 40-44. http://dx.doi.org/10.1016/j.sbspro.2014.04.076

Valeeva, R. A., Koroleva, N. E., \& Sakhapova, F. Kh. (2014). Civic education of the technical university students in foreign language classes. Review of European Studies, 7(1), $176-181$. http://dx.doi.org/10.5539/res.v7n1p176

Vlasova, V. K., Kirilova, G. I., \& Masalimova, A. R. (2015). Information and Logistic Foundations of Pedagogical Education Design and Content Education. Review of European Studies, 4(7), 54-58. http://dx.doi.org/10.5539/res.v7n4p54

Zimnaya, I. A. (2006). Competence approach. What is its place in the modern approaches to education? (Theoretical and methodological aspect). Higher education today: The reform, innovation, experience, 8, 20-26.

Zhukov, Y. M., Petrovskaya, L. A., \& Rastyannikov, P. V. (1990). Diagnosis and development of competence in communication. Moscow: Moscow State University.

Zverev, I. D., \& Maksimov, V. N. (1987). Interdisciplinary communication in the educational process of modern school. Moscow: Prosvieshchenie.

\section{Copyrights}

Copyright for this article is retained by the author(s), with first publication rights granted to the journal. This is an open-access article distributed under the terms and conditions of the Creative Commons Attribution license (http://creativecommons.org/licenses/by/3.0/). 